\title{
Transação Tributária e Extrafiscalidade: uma abordagem à luz do controle de proporcionalidade
}

\author{
Tax Transactions and Extrafiscality: an approach in the light of \\ proportionality control
}

\author{
Ubaldo Cesar Balthazar ${ }^{1}$ \\ Hendrick Pinheiro ${ }^{2}$ \\ Bruno Bartelle Basso ${ }^{3}$ \\ ${ }^{1}$ Universidade Federal de Santa Catarina, Florianópolis, SC, Brasil \\ ${ }^{2}$ Universidade de São Paulo, São Paulo, SP, Brasil \\ ${ }^{3}$ Pontifícia Universidade Católica de São Paulo, São Paulo, SP, Brasil
}

Resumo: Este artigo realiza uma breve reflexão acerca dos programas de transação tributária desenvolvidos no Brasil, à luz do controle de proporcionalidade. Para tanto, serão analisados o instituto previsto no artigo 171 do Código Tributário Nacional (CTN) e o contexto histórico em que ele se encontra inserido, para, posteriormente, confrontá-lo com o princípio da igualdade, a fim de demonstrar que a proporcionalidade pode ser utilizada como um critério legítimo para o controle de políticas públicas indutoras de comportamento dos contribuintes, notadamente, a partir do preenchimento dos critérios da adequação, da necessidade e da proporcionalidade em sentido estrito.

Palavras-chave: Transação Tributária. Extrafiscalidade. Controle de Proporcionalidade.
Abstract: The purpose of this article is to give a brief reflection about the taxation programs developed in Brazil, in the light of proportionality control. For this purpose, the institute established in art. 171 of the National Tax Code (CTN) and the historical context in which it is inserted, and then to confront it with the principle of equality, in order to demonstrate that proportionality can be used as a legitimate criterion for the control of policies taxpayers' behavior, notably from the fulfillment of the criteria of adequacy, necessity and proportionality in the strict sense.

Keywords: Tax Transactions. Extrafiscal Objectives. Proportionality Control.

Recebido em: 19/06/2019

Revisado em: 18/05/2020

Aprovado em: 27/05/2020

Direito autoral e licença de uso: Este artigo está licenciado sob uma Licença Creative Commons.Com essa licença você pode compartilhar, adaptar, para qualquer fim, desde que atribua a autoria da obra, forneça um link para a licença, e indicar se foram feitas alterações. 


\section{Introdução}

Segundo relatório elaborado pelo Conselho Nacional de Justiça (2017, p. 113), as execuções fiscais representam 38\% dos processos pendentes no Judiciário brasileiro, evidenciando que a desídia no enfrentamento desses problemas converte a mera letargia política num problema que se agrava constantemente, corporificando as desigualdades sociais e o chamado "custo-Brasil" (MACHADO; BALTHAZAR, 2017, p. 223).

Somado a esses problemas, verifica-se a adoção de uma postura extremamente autoritária por parte de alguns agentes do fisco, que, muitas vezes, abusando das suas prerrogativas de físcalização, assumem um verdadeiro perfil policialesco, revelando ângulos de uma desigualdade na qual o domínio do mais forte se constitui em constante elemento lesivo contra o mais frágil (COSTA, 2001, p. 196). Essa visão unilateral e autoritária da tributação pode ser atribuída a uma sacralização da interpretação da legislação tributária pelo fisco, sempre tido por detentor da verdade e paladino das benfeitorias sociais (BALTHAZAR; ROSSINI, 2016, p. $683)$.

Entre algumas medidas adotadas pelo fisco para a tentativa de diminuição da litigiosidade, encontram-se os programas de "parcelamento" incentivados, que são estruturados na forma de verdadeiras transações tributárias (MACHADO, 2008, p. 121), pois estabelecem um conjunto de condições favoráveis aos participantes, de modo a induzir o comportamento dos contribuintes, acenando com uma vantagem econômica em favor da pessoa sujeita à imposição (CORREA, 1964, p. 48-49). No âmbito federal, apenas nos últimos 17 anos, é possível identificar, ao menos, nove edições desses programas, com diferentes configurações.

A questão que se afigura, entretanto, não é propriamente a de se analisar o modo pelo qual a transação tributária vem sendo tratada pelo legislador pátrio, mas, sim, se, ao serem instituídos, esses programas se encontram regulando, legitimamente, a paridade de armas dos contribuintes na atuação no domínio econômico.

Dito de outro modo: se há um controle de proporcionalidade em relação a essas normas jurídicas, em que se resguarde, na prática, o prin- 
cípio da igualdade tributária, no âmbito da administração pública consensual, por intermédio da qual o particular passa a participar do processo de construção do meio de implementação do interesse público em situações concretas, pautando-se na premissa de inviabilidade de o Poder Público concentrar em si o exercício dos misteres públicos (LOUBET, 2009, p. 82).

São essas as razões que nos levam a tratar do tema não apenas do ponto de vista tributário - como, normalmente, é feito -, mas, em especial, a partir de um outro referencial teórico - em que se busca no controle da proporcionalidade o assento necessário e suficiente para assim proceder -, tendo em vista que que os tributos são o mais importante instrumento, pelo qual o sistema político põe em prática o seu conceito de justiça distributiva ou econômica (MURPHY; NAGEL, 2002, p. 3).

\section{Os Programas de Transação Tributária no Contexto da Admi- nistração Pública Consensual}

A utilização de instrumentos tributários para induzir o comportamento dos contribuintes não é recente. A tributação - como elemento integrante da política físcal - revela-se como verdadeira caixa de ferramentas à disposição do Estado na busca de seus objetivos, figurando a transação tributária apenas como mais um desses instrumentos. Essa mudança de postura do Estado para um papel de agente de realizações que se reportam principalmente ao domínio econômico (FARIA, 2010, p. 66) é fator primordial para o surgimento do Estado Social de Direito (LEÃO, 2015, p. 40).

A partir de então, é indene de dúvidas de que o Estado passa a desenvolver também uma função promocional-indutora, incitando os contribuintes a realizarem determinadas condutas, mediante o oferecimento de certas vantagens econômicas. $\mathrm{O}$ uso do instrumento tributário em sentido extrafiscal tornou-se, na realidade, um dever constitucional do Estado. Ao invés de ser um mero espectador dos problemas que se referem ao ambiente econômico e social, o Estado expressamente adotou essa postura ativa e dinâmica, em detrimento de uma postura passiva e estática (GIULIANI FONROUGE, 1976, p. 17). 
Assim, enquanto na maior parte das imposições procura-se, ao máximo, buscar a neutralidade na tributação, na extrafiscalidade verifica-se o propósito de agravar o aludido efeito, a fim de que ele represente um estímulo realmente provocador de uma alteração de comportamento (CORREA, 1964, p. 50). A indução, em verdade, é a antítese da neutralidade (ZILVETI, 2005, p. 26).

No Brasil, as normas gerais sobre a transação tributária encontram-se previstas no artigo 171 do Código Tributário Nacional (CTN). Por meio desse dispositivo, o legislador facultou ao fisco e aos contribuintes a realização de um negócio jurídico que, mediante concessões recíprocas, pudesse eliminar o litígio e satisfazer o crédito tributário de maneira mais célere.

Há quem sustente que a transação tributária poderia ser utilizada como um canal de diálogo entre o fisco e o contribuinte, com vistas a resolver conflitos derivados do processo de positivação do crédito tributário (TORRES, 1998, p. 50), em muitos casos atribuível à dificuldade de interpretação e de aplicação de conceitos jurídicos indeterminados (COSTA, 2007, p. 53). Para outros, esse instituto, como operaria sobre obrigações existentes, não serviria para reabrir a discussão sobre a legalidade do crédito tributário conforme constituído (ROCHA, 2005, p. 106), tendo sua aplicação limitada a induzir o contribuinte à satisfação voluntária da obrigação (SANTI, 2008, p. 174).

Independentemente da visão sobre o alcance da transação tributária no ordenamento jurídico brasileiro, é de se observar que a manifestação mais comum desse instituto ocorre nos programas de "parcelamento" incentivados, nos quais se estabelecem um conjunto de condições favoráveis aos participantes, de modo a induzir o comportamento do contribuinte, acenando com uma vantagem econômica em favor da pessoa sujeita à imposição.

Nesses programas, o estímulo indutivo é premeditado pelo legislador, existindo a intenção consciente de provocar a adesão do contribuinte. Trata-se, como se vê, de um ato administrativo negocial que contém em sua origem um negócio jurídico firmado entre fisco e contribuinte, para o cumprimento voluntário da obrigação, nos termos pactuados (SILVA; RIBAS, 2015, p. 171). 
Cria-se, com isso, uma relação de reciprocidade com o contribuinte: se este agir de acordo com a finalidade, será recompensado; se agir de forma contrária, não o será (STÖZEL, 2002, p. 194). Essa perspectiva de colaboração na formação do ato transacional representa uma dimensão de interesse público não autoritária, na qual a força e a coerção na cobrança do crédito tributário são substituídas pelo consenso.

Em lugar da Administração monológica, avessa à comunicação com a sociedade, erige-se uma Administração dialógica, paritária e consensual; em lugar do Estado impositor, apresenta-se o Estado mediador (OLIVEIRA; SCHWANKA, 2008, p. 276-277). Essa noção de permeabilidade à colaboração pode ser atribuída a um processo de processualização da atividade administrativa, no seio da qual a formação da decisão pública abandona uma visão de hierarquia da administração em relação aos administrados, típica de um modelo de estado liberal, para adotar, no estado pós-social, uma dimensão de colaboração e imparcialidade consubstanciada pela abertura à participação (DUARTE, 1996, p. 36).

Entender os programas de transação tributária, assim como um mecanismo alternativo na resolução de conflitos tributários, é aceitar, também, a possibilidade de uma administração aberta à participação, na qual há espaço para diálogo entre físco e contribuintes (DACOMO, 2009, p. 116).

Tal perspectiva é condizente com uma dimensão plural do interesse público, que recusa uma construção principiológica abstrata em prol de uma visão prospectiva, preocupada com a eficiência e efetividade dos resultados almejados e que visa à edição de atos mais permeáveis para a consideração dos interesses dos administrados. Trata-se de um olhar que considera os impactos das alternativas consideradas, que aceita a possibilidade de uma unilateralidade reflexiva, ponderando as posições conflitantes e a vontade do administrado no momento da produção dos atos administrativos (MARQUES NETO, 2011).

A Administração Pública, sob essas lentes, é instada a participar do processo de construção (densificação) da normatividade, ao invés de lhe ser apenas conferido o papel de aplicadora mecânica da lei, à luz de uma legalidade rígida e fechada. Esse modelo tradicional de vinculação à lei é 
substituído por outro no qual prepondera a normatividade aberta e a parcialmente indeterminada, com o incremente do uso das denominadas normas administrativas em branco (OTERO, 2003, p. 894).

A utilização de instrumentos tributários para a implementação de objetivos específicos, por sua vez, deve respeitar as limitações inerentes à tributação, cabendo, entre outros aspectos, dar destaque, inicialmente, ao papel do princípio da igualdade na veiculação de programas indutores de comportamentos dos contribuintes.

\section{O Princípio da Igualdade e as Normas Tributárias com Objetivos Extrafiscais}

O princípio da igualdade é o mandamento nuclear do sistema jurídico constitucional. É ele a primeira base de todos os princípios constitucionais e condiciona a própria função legislativa, que é a mais nobre, alta e ampla de quantas funções o povo, republicanamente, decidiu criar (ATALIBA, 2015, p. 159). A igualdade constitui o signo fundamental da democracia (SILVA, 2011, p. 211), pois é o princípio constitucional de onde parte a fundamentação necessária da validade de todas as leis (CARRAZA, 2015, p. 31).

Ao Estado não é dado fazer qualquer distinção entre aqueles que se encontram sob seu manto, salvo se o critério diferenciador estiver adequado à concretização do fim estatal (ÁVILA, 2012, p. 138) e servindo a um propósito legítimo (MURPHY; NAGEL, 2002, p. 165). É o que preleciona a ordem constitucional vigente, notadamente por meio do inciso I do artigo $5^{\circ}$ e do inciso II do artigo 150, ambos da Constituição Federal de 1988.

Não se ateve o constituinte, entretanto, simplesmente, a proclamar a igualdade no plano formal, mas a emprestar-lhe a máxima concreção, de maneira a assegurar a igualdade material ou substancial, a fim de torná-la um valor vivo e presente, a ser incessantemente perseguido pela sociedade, não só por meio de leis, mas também pela aplicação de políticas ou programas de ação estatal (COMPARATO, 1996, p. 59), cabendo ao 
intérprete percorrer, basicamente, três etapas, para concretizá-la no plano real: encontrar um critério; buscar a fundamentação constitucional para o critério encontrado; e, por último, comparar as situações a partir do critério eleito (ÁVILA, 2005, p. 418).

Sob essa ótica, se faz necessário investigar, de um lado, aquilo que é adotado como critério discriminatório, e, de outro, verificar se há justificativa racional, isto é, fundamento lógico, para, à vista do traço desigualador acolhido, atribuir o específico tratamento jurídico construído em função da desigualdade proclamada. Impende analisar, ainda, se a correlação ou o fundamento racional abstratamente existente é in concreto, afinado com os valores prestigiados no sistema normativo constitucional (BANDEIRA DE MELLO, 2017, p. 21). É que a lei, embora aplicada de modo uniforme, pode conter uma distinção arbitrária em seu conteúdo (WESTEN, 1990, p. 76).

A identificação de parâmetros constitucionalmente aceitáveis e de elementos que evidenciem a medida de discriminação é a pedra de toque para a correta verificação dos critérios utilizados pelo legislador diante de um caso concreto. A questão da igualdade só se complementa com a introdução do elemento indicativo da medida de comparação e com a exigência de relação de congruência não só entre ele e a medida de comparação, como entre a medida de comparação e a finalidade que justifica a sua utilização (ÁVILA, 2015, p. 50). A discriminação pressupõe, de fato, critérios de pertinência, de coerência lógica e de razoabilidade (OLIVEIRA, 2003, p. 48).

A igualdade, portanto, nada mais é do que uma verdadeira proibição de arbitrariedade (LEIBHOLZ, 1959, p. 72) exigindo que pessoas que estejam sujeitas a um determinado imposto e se encontrem em condições semelhantes e relevantes a efeitos fiscais devam receber um tratamento fiscal semelhante (NEUMARK, 1994, p. 135). Sem essas premissas, não se pode, efetivamente, definir o conteúdo imanente à isonomia tributária.

Nesse contexto, a injustiça da norma tributária encontra-se na circunstância de se tratar diferentemente os contribuintes, que até eram descritivamente diferentes, mas sem a razão justificadora, sem a consi- 
deração adequada das diferenças relevantes, ou com a consideração de diferenças irrelevantes (ÁVILA, 2015, p. 26).

É possível conceituar a finalidade fiscal como a técnica que busca extrair do patrimônio dos particulares o dinheiro necessário para que o Estado possa cumprir com suas finalidades voltadas para o interesse público (BALTHAZAR, 2011, p. 234). Quando se trata de normas tributárias fiscais, a capacidade contributiva se apresenta, invariavelmente, como critério de diferenciação dos contribuintes (TABOADA, 2005, p. 243), com o intuito de realizar justiça fiscal (COSTA, 2012, p. 17) e assegurar a justiça distributiva, tendo como fundamento constitucional o $\S 1^{\circ}$ do artigo 145 da Constituição Federal de 1988.

O questionamento que se impõe, contudo, é se, no caso de normas tributárias extrafiscais, a capacidade contributiva, também, poderia ser utilizada como parâmetro ou se ela deveria ser conjugada com outros critérios, especialmente o da proporcionalidade.

Embora existam autores que defendam que a extrafiscalidade não tenha nenhuma relação com o princípio da capacidade contributiva, na medida em que não seria possível justificar a extrafiscalidade pela capacidade do cidadão de pagar o tributo (ZILVETI, 2004, p. 196), entende-se que cabe ao intérprete compatibilizá-la com as normas tributárias indutoras em uma relação de nítida integração (SCHOUERI, 2005, p. 290), de modo a resguardar a manutenção do mínimo vital, o não atingimento do confisco e o não cerceamento de outros direitos constitucionais (COSTA, 2012, p. 77), principalmente por meio do exame de proporcionalidade.

Os objetivos extrafiscais jamais poderiam legitimar o gravame de uma riqueza situada fora dos limites para a sua aplicação. Seria injusta e arbitrária qualquer imposição que prescindisse por completo da capacidade contributiva dos contribuintes (OLLERO, 1991, p. 141). Por essas razões, e em que pese as normas tributárias indutoras se afastarem da capacidade contributiva como critério geral, não parece possível defender a inexistência de qualquer relação entre extrafiscalidade e capacidade contributiva (LEÃO, 2015, p. 113). 
A norma tributária indutora, aliás, precisa trabalhar - de forma eficaz - na remoção dos obstáculos que determinam as situações de desigualdade (FERRAZ, 2009, p. 25), notadamente por meio da utilização do critério da proporcionalidade, porque, direta ou indiretamente, as normas interventivas reduzem a esfera privada do contribuinte atingindo seus direitos de liberdade, de propriedade, de dignidade e de outros bens conforme seu âmbito de atuação (ÁVILA, 2012, p. 141).

Seria, no mínimo, incoerente que o legislador tributário, a quem é facultado utilizar-se da norma tributária para a correção de falhas do mercado ou para a busca de objetivos prestigiados pela ordem econômica, fosse ele mesmo o causador dessas falhas, contribuindo para as desigualdades que deveria combater (SCHOUERI, 2007, p. 254).

Para se afastar a presunção de igualdade não seria suficiente, então, justificar; seria preciso confirmar que a medida do distanciamento da igualdade é proporcional; e, para evidenciá-lo, seria preciso comprovar que a medida produz efeitos que contribuem para a realização gradual da finalidade extrafiscal (exame da adequação), que a medida é menos restritiva aos direitos envolvidos, entre aquelas que poderiam ter sido utilizadas para atingir a finalidade extrafiscal (exame da necessidade), e que os efeitos positivos, decorrentes da adoção da medida, aferidos pelo grau de importância e de promoção da finalidade extrafiscal, não são desproporcionais aos seus efeitos negativos, estimados pelo grau de importância e de promoção da finalidade igualitária (exame da proporcionalidade em sentido estrito) (ÁVILA, 2015, p. 168).

É com assento nesses fundamentos que passaremos a analisar a proporcionalidade como critério legítimo para o controle da extrafiscalidade.

\section{A Proporcionalidade como Critério Legítimo para o Controle da Extrafiscalidade}

O legislador tributário, no exercício de sua competência, goza de certa liberdade na elaboração de programas, implementados via política fiscal, para obtenção de objetivos extrafiscais. Todavia, essa liberdade 
não é absoluta. Nesse contexto, surge a proporcionalidade como um limitador da atividade do Estado (BALTHAZAR; VIEIRA, 2013, p. 180).

A aplicação de normas e de princípios jurídico-constitucionais, em hipóteses em que se apresente aparente conflito, reclama procedimentos institucionalizados com vistas a garantir sua concordância prática, de tal modo que os bens jurídicos protegidos sejam realizados em sua eficácia ótima (HESSE, 1998, p. 67).

Por procedimento não se deve compreender apenas o conjunto de normas e de instituições envolvidas na interpretação de aplicação do direito. Também o integram as ferramentas cognitivas por meio das quais se dá o confronto das diferentes argumentações, relativas às inúmeras possibilidades de interpretação, por meio das quais são criadas condições para o debate e a formação de uma decisão de aplicação, cuja racionalidade possa ser submetida ao controle, a partir de sua fundamentação objetiva (GUERRA FILHO, 2001, p. 269).

A extrafiscalidade pressupõe a utilização de instrumentos tributários para a realização de objetivos que transcendem à realização das finalidades intrínsecas do sistema tributário. Nesse processo, a realização de princípios orientadores da atividade tributária - como a capacidade contributiva - é mitigada em favor da concretização de outros valores integrantes do ordenamento jurídico. A proporcionalidade surge como procedimento lógico-dialético para a conformação dos princípios em aparente conflito.

Em uma perspectiva constitucional, Canotilho (1998, p. 260) aponta como origem do princípio da proporcionalidade - que denomina proibição do excesso - a necessidade de limitação do poder executivo, figurando, como medida para as restrições administrativas, a liberdade individual. Em sua feição atual, o autor compreende esse poder como um princípio de controle exercido pelos tribunais quanto à adequação dos meios administrativos (sobretudo coactivos) para a prossecução do escopo e o balanceamento concreto dos direitos ou interesses em conflito.

Os programas que se valem de instrumentos tributários extrafiscais consistem em meios administrativos destinados ao atendimento de objetivos específicos. A utilização de normas tributárias indutoras na busca pe- 
los objetivos pretendidos revela-se como uma potencial fonte de conflito entre direitos e interesses dos indivíduos envolvidos.

A proporcionalidade pode ser construída como uma decorrência do princípio do estado de direito (HESSE, 1998, p. 159). Nesse contexto, sua utilização como critério de racionalidade na interpretação das normas tributárias indutoras converte-se em instrumento que viabiliza o controle dos motivos materiais que legitimam a prevalência do princípio externo ao sistema tributário protegido em decorrência dos valores que fundamentam a atividade fiscal do Estado.

Como preconiza Robert Alexi (2005), as relações de prioridade entre princípios não são absolutas, mas condicionais e relativas. A possibilidade de reconstrução das razões que justificaram a elaboração de determinado programa de transação tributária viabiliza seu controle. Submeter tais razões a um juízo de proporcionalidade tem por objetivo verificar se a promoção do valor protegido garante a manutenção de um mínimo de respeito ao núcleo essencial de outros valores sacrificados (GUERRA FILHO, 2001, p. 269).

A análise de proporcionalidade nas normas tributárias indutoras (extrafiscais) busca a racionalidade na relação entre meios e fins. Sua operacionalização tem em vista um fim, que pode ser atingido por diversos meios, entre os quais haverá de escolher o intérprete (GUERRA FILHO, 2001, p. 270). Todavia, como explica Marta Leão (2015, 139), essa racionalidade transcende a relação meio-fim para englobar também a análise do grau de restrição aos direitos fundamentais envolvidos.

A análise de proporcionalidade em relação às normas tributárias com função indutora revela-se como importante mecanismo de proteção da igualdade dos contribuintes. Isso, porque as normas tributárias, na perspectiva de sua função extrafiscal, representam um potencial conflito de igualdade, já que separam os contribuintes em dois grupos: um primeiro formado pelos seus destinatários, que será por elas atingido com vista a estimular ou desestimular determinados comportamentos; e um segundo grupo formado pelos não destinatários, aqueles contribuintes que já adotam o comportamento estimulado. Esses grupos são entre si excludentes (FOLLONI, 2014). 
Em tal contexto, o juízo de proporcionalidade tem como propósito avaliar a justificação dos critérios de desigualdade impostos a esses dois grupos de contribuintes, desdobrando-se em três aspectos, a saber: a adequação (ou conformidade); a necessidade (ou exigibilidade) e a proporcionalidade em sentido estrito

Um juízo de adequação - ou conformidade - verifica se a medida escolhida é apropriada para a realização dos fins a que se destina, em uma relação de meio-fim (CANOTILHO, 1998, p. 262). A adequação representa um juízo de utilidade em relação à medida escolhida (GUERRA FILHO, 2001, p. 270).

A necessidade - ou exigibilidade - demanda uma postura de menor ingerência possível ou menor desvantagem possível. Assim, na escolha dos meios para a realização dos fins, uma análise de necessidade exige que seja adotada a via menos onerosa ao cidadão, ou seja, se é aquela menos agressiva "[...] dos bens e valores constitucionalmente protegidos, que porventura colidem com aquele consagrado na norma interpretada" (GUERRA FILHO, 2001, p. 270).

Nesse contexto, o meio escolhido deve ser aquele que menos restringe os direitos fundamentais envolvidos (exigibilidade material); cuja aplicação se limite ao âmbito espacial necessário à intervenção (exigibilidade espacial); que pressupõe uma rigorosa delimitação temporal da medida (limitação temporal); e cuja eficácia limitadora atinja o menor número de indivíduos (exigibilidade pessoal) (CANOTILHO, 1998, p. 262).

Por fim, no que tange à proporcionalidade em sentido estrito, esta diz respeito ao resultado da intervenção. Um juízo dessa natureza se volta para a carga coativa, com vistas a pesar as desvantagens dos meios em relação às vantagens dos fins (CANOTILHO, 1998, p. 262).

Estabelecidas essas bases, propõe-se a utilização da proporcionalidade para se investigar a justificação dos critérios de desigualdade introduzidos no sistema por determinado programa de transação tributária, com o intuito de confrontá-los com os objetivos que se pretende, de fato, atingir. 


\section{O Controle de Proporcionalidade em Programas de Transação Tributária}

Os programas de transação tributária representam, a priori, uma ofensa potencial ao princípio da isonomia, pois propõem uma discriminação entre dois grupos de sujeitos: aqueles que cumpriram suas obrigações tributárias a seu tempo e modo e os recalcitrantes. Concedem, em regra, um tratamento mais benéfico aos inadimplentes que deixaram de cumprir as obrigações sem considerar que, nas mesmas condições adversas, os demais se esforçaram para cumpri-las (TAVARES, 2001). Em tais situações, essa desigualdade pode ser vista como uma restrição ao direito fundamental de paridade de armas na atuação no domínio econômico.

Em sede de adequação das medidas, o controle dos programas de transação tributária visa a confrontar a adequação do meio escolhido com os fins obtidos, convolando-se em um juízo de proporcionalidade (ÁVILA, 2011, p. 177). Esse juízo de conformidade confronta as condições oferecidas aos contribuintes inadimplentes e as exigências impostas para a adesão (meios) com os objetivos almejados com os programas.

No campo das condições oferecidas pelo fisco, a inadequação dessas exigências poderia causar a frustração de seus objetivos iniciais pela não adesão dos contribuintes aos programas de transação tributária. Isso, porque, caso não entendam vantajoso, os contribuintes podem simplesmente permanecer na mesma condição de inadimplentes. Nesse caso, restaria, pois, frustrada a intensão indutora do legislador.

Já no terreno das exigências impostas aos contribuintes, exigir sacrifícios que não estejam diretamente relacionados aos fins colimados como a renúncia ao direito de discutir em juízo a legalidade do crédito tributário - se mostra, do mesmo modo, desproporcional e inadequado. Nesse caso, aliás, para além de uma ofensa ao princípio da inafastabilidade da jurisdição, tal exigência revelar-se-ia inadequada ao atendimento do fim precípuo da transação tributária, que é, justamente, o de viabilizar a recondução do contribuinte a uma situação de regularidade fiscal.

No campo da necessidade, o juízo sobre a pertinência dos programas de transação tributária deriva diretamente do cálculo entre o déficit 
de igualdade que se provocará entre os contribuintes adimplentes e os inadimplentes. O exemplo do Programa Especial de Regularização Tributária (PERT), instituído pela Lei n. 13.496/2017 (BRASIL, 2017), nesse aspecto, é profícuo, pois invoca duas considerações diversas sobre o mesmo juízo da necessidade da medida, especialmente quando permite a utilização de prejuízos fiscais acumulados para a quitação de débitos tributários em atraso (BRASIL, 2017, art. $2^{\circ}$, I e quando estabelece regras acerca de anistia e de remissão dos juros de mora e das multas de mora, de ofício ou isoladas (BRASIL, 2017, art. $2^{\circ}$, III).

No campo da tributação sobre a renda, a possibilidade de compensação de prejuízos fiscais pode ser vista como uma medida anticíclica (LEMGRUBER, 2004, p. 216), que visa a equilibrar a necessidade de um critério temporal, necessário à garantia da manutenção de um fluxo de recursos para o financiamento estatal, com a tributação da capacidade contributiva por meio da renda nas pessoas jurídicas, evitando que a tributação consuma a própria fonte do rendimento em períodos deficitários.

Nota-se que a utilização do critério da possibilidade de compensação de prejuízos, em um programa que pretendia justamente fornecer auxílio a empresas em um momento de crise econômica, mostra-se adequado, por viabilizar a absorção mais rápida de resultados negativos, liberando, assim, recursos para a manutenção da atividade econômica. Note-se que a desigualdade estabelecida é apenas temporal, posto que adimplentes e inadimplentes poderiam compensar no tempo o prejuízo acumulado em determinado exercício com o lucro dos exercícios subsequentes.

O PERT, de outro modo, ao estabelecer regras de anistia e de remissão - que podem alcançar o patamar de $90 \%$ (noventa por cento) dos juros de mora e $70 \%$ (setenta por cento) das multas de mora, de ofício ou isoladas - estabelece uma condição de desigualdade mais severa se comparada à situação dos contribuintes adimplentes. Nesse caso, pode-se identificar um benefício mais evidente aos inadimplentes, supostamente justificada nos benefícios de estímulo à atividade econômica, que pode ser sindicada à luz da proporcionalidade. 
No que tange à proporcionalidade em sentido estrito, a análise dos programas de transação tributária deve considerar os benefícios e os prejuízos provocados aos direitos fundamentais envolvidos, em especial, os atinentes aos destinatários do programa e dos demais contribuintes. Isso, porque a limitação a um direito fundamental não poderá ser considerada proporcional em sentido estrito se o dano causado extrapola o benefício auferido (BARAK, 2012, p. 340-343), tendo em vista que o juízo de restrição visa a proteger os contribuintes de atuações casuísticas, destinadas exclusivamente a beneficiar ou prejudicar determinados grupos econômicos específicos (SCHOUERI, 2005, p. 54).

Em relação ao PERT, é possível auferir a busca pelo equilíbrio entre os benefícios conferidos aos destinatários do programa - contribuintes que ostentam débitos perante o governo federal - e o déficit de igualdade provocado em relação aos demais contribuintes, que se mantiveram em uma situação de inadimplência, não estando inquinado, a princípio, de uma ilegalidade aparente em relação ao terceiro quesito de controle de proporcionalidade.

\section{Conclusão}

Os programas de transação tributária devem ser analisados não mais apenas do ponto de vista tributário, mas, principalmente, à luz de seus objetivos extrafiscais, de modo a permitir que a Administração Pública possa resguardar a igualdade, por meio das políticas públicas indutoras de comportamento dos contribuintes

Sob essas lentes, se faz imprescindível utilizar critérios que permitam, tanto ao fisco quanto aos contribuintes, o controle legítimo dessas medidas institucionais, especialmente para poder se aferir a adequação (ou conformidade), a necessidade (ou exigibilidade) e a proporcionalidade em sentido estrito, a fim de prestigiar e de valorizar um diálogo mais efetivo entre os participantes do regime democrático de direito.

A par dessas premissas, não há dúvidas de que o controle de proporcionalidade dos programas de transação tributária se torna de fundamental importância em uma sociedade que deve ver a arrecadação com 
respeito ao ser humano e não como um simples ato de força estatal, em benefício apenas dos detentores do poder (BECHO, 2009, p. 343).

Este estudo não tem por objetivo apresentar uma fórmula invariável, ou sindicar a legalidade ou constitucionalidade de programas existentes, mas apenas ressaltar a importância do juízo de proporcionalidade como método, para analisar as situações de desigualdade impostas pelos programas de parcelamento incentivados em suas mais diferentes configurações.

A intenção aqui é defender que não haveria problema em oferecer condições mais favoráveis com o objetivo (extrafiscal) declarado de induzir os contribuintes com débitos em atraso a cumprir suas obrigações. Todavia, a forma e a intensidade desses incentivos devem ser ponderadas no sentido de evitar uma agressão demasiada sobre o direito a um tratamento equânime, garantido pela fiscalidade aos contribuintes que cumpriram suas obrigações em dia.

\section{Referências}

ALEXI, Robert. Sobre a estrutura dos princípios jurídicos. Revista Internacional de Direito Tributário, Belo Horizonte, p. 155-167, jan.jun. 2005.

ATALIBA, Geraldo. República e Constituição. 3. ed. São Paulo: Malheiros Editores, 2015.

ÁVILA, Humberto Bergmann. O princípio da isonomia em matéria tributária. In: TÔRRES, Heleno Taveira (coord.). Tratado de direito constitucional tributário: estudos em homenagem a Paulo de Barros Carvalho. São Paulo: Saraiva, 2005. p. 407-439.

ÁVILA, Humberto Bergmann. Sistema Constitucional Tributário. 5. ed. São Paulo: Saraiva, 2012.

ÁVILA, Humberto Bergmann. Teoria da Igualdade Tributária. 3. ed. São Paulo: Malheiros Editores, 2015. 
ÁVILA, Humberto. Teoria dos princípios, da definição à aplicação dos princípios jurídicos. 12. Ed. São Paulo: Malheiros, 2011.

BALTHAZAR, Ubaldo Cesar; ROSSINI, Guilherme de Mello. Uma proposta de (re)leitura da noção de interesse público: os privilégios implícitos da fazenda pública em xeque. Rev. Fac. Direito UFMG, Belo Horizonte, n. 69, p. 657-686, jul.-dez. 2016.

BALTHAZAR, Ubaldo Cesar; VIEIRA, Carolina Sena. A desproporcionalidade da adoção do "valor da operação" como base de cálculo das multas por descumprimento de deveres instrumentais tributários. Prisma Jurídico, São Paulo, v. 12, n. 1, p. 155-200, jan.-jun. 2013.

BALTHAZAR, Ubaldo Cesar. A resistência ao pagamento de tributos no Brasil. Uma breve análise histórica e humanística. In: BOMBASSARO, Luiz Carlos; DAL RI JÚNIOR, Arno; PAVIANI, Jayme (Org.). As interfaces do Humanismo Latino. Porto Alegre: EdiPUCRS, 2004. p. 169-186.

BALTHAZAR, Ubaldo Cesar. Tributos e meio ambiente. Espaço Jurídico, Joaçaba, v. 12, n. 2, p. 233-244, jul.-dez. 2011.

BANDEIRA DE MELLO, Celso Antônio. O conteúdo jurídico do princípio da igualdade. 3. ed. São Paulo: Revista dos Tribunais, 2017.

BARAK, Aharon. Proportionality: constitucional rights and their limitation. Trad. Doron Kalir. New York: Cambridge University Press, 2012. p. 340-343.

BECHO, Renato Lopes. Filosofia do Direito Tributário. São Paulo: Saraiva, 2009. p. 341.

BRASIL. Lei Federal n. 13.463, de 24 de outubro de 2017. Disponível em: http:/www.planalto.gov.br/ccivil_03/_ato2015-2018/2017/Lei/ L13496.htm. Acesso em: 6 fev. 2018.

CANOTILHO, J. J. Gomes. Direito constitucional e teoria da constituição. 2. ed. Coimbra: Almedina, 1998.

CARRAZA, Elizabeth Nazar. IPTU e Progressividade: igualdade e capacidade contributiva. 2. ed. São Paulo: Quartier Latin, 2015. 
COMPARATO, Fábio Konder. Direito Público: estudos e pareceres. São Paulo: Saraiva, 1996.

CONSELHO NACIONAL DE JUSTIÇA - CNJ. Justiça em Números 2017: ano-base 2016. Brasília, DF: Conselho Nacional de Justiça, 2017. CORREA, Walter Barbosa. Contribuição ao Estudo da Extrafiscalidade. São Paulo: USP, 1964. p. 48-49.

COSTA, Nelmo de Souza. Legalidade tributária e prática fiscal. 2011. 256f. Dissertação (Mestrado) - Universidade Federal de Santa Catarina, Centro de Ciências Jurídicas. Curso de Pós-Graduação em Direito, Florianópolis, 2001.

COSTA, Regina Helena. Praticabilidade e justiça tributária, exequibilidade da Lei Tributária e Direitos do Contribuinte. São Paulo: Malheiros, 2007.

COSTA, Regina Helena. Princípio da Capacidade Contributiva. 4. ed. São Paulo: Malheiros Editores, 2012.

DACOMO, Natalia de Nardi. Direito tributário participativo, transação e arbitragem administrativas da obrigação tributária. São Paulo: Quartier Latin, 2009.

\section{DUARTE, David. Procedimentalização, participação e}

fundamentação: para uma Concretização do Princípio da Imparcialidade Administrativa como Parâmetro Decisório. Coimbra: Almedina, 1996.

FARIA, Luiz Alberto Gurgel de. A extrafiscalidade e a concretização do princípio da redução das desigualdades regionais. São Paulo: Quartier Latin, 2010. p. 66.

FERRAZ, Roberto. O princípio da Capacidade Contributiva na Tributação Ambientalmente Orientada. In: FERRAZ, Roberto (coord.). Princípios e Limites da Tributação 2: os princípios da Ordem Econômica e a Tributação. São Paulo: Quartier Latin, 2009. p. 517-561. FOLLONI, André. Isonomia na tributação extrafiscal. Revista Direito GV, São Paulo, n. 19, p. 201-220, jan.-jun. 2014. 
GIULIANI FONROUGE, Carlos M. Derecho Financeiro. 3. ed. Buenos Aires: Depalma, 1976. v. 1. p. 17.

GUERRA FILHO, Willis Santiago. Princípio da proporcionalidade e teoria do direito. In: GRAU, Eros Roberto; GUERRA FILHO, Willis Santiago (org.). Direito constitucional, estudos em homenagem a Paulo Bonavides. São Paulo: Malheiros, 2001. p. 268-283.

HESSE, Konrad. Elementos de direito constitucional da república federal da Alemanha. Porto Alegre: Sergio Antonio Fabris Editor, 1998.

LEÃO, Martha Toribio. Controle da Extrafiscalidade: Série Doutrina Tributária. São Paulo: Quartier Latin, 2015. v. XVI.

LEIBHOLZ, Gerhard. Die Gleichheit vor dem Gesetz. München: C.H. Beck, 1959.

LEMGRUBER, Andrea. A tributação do capital: o Imposto de Renda da Pessoa Jurídica e o Imposto sobre Operações Financeira. In: BIDERMAN, Ciro; ARVATE, Paulo (coord.). Economia do setor público no Brasil. Rio de Janeiro: Campos, 2004. p. 206-215.

LOUBET, Wilson Vieira. O princípio da indisponibilidade do interesse público e a administração consensual. Brasília, DF: Consulex, 2009, p. 82.

MACHADO, Carlos Henrique; BALTHAZAR, Ubaldo Cesar. A Reforma Tributária como Instrumento de Efetivação da Justiça Distributiva: uma abordagem histórica. Revista Seqüência - Estudos Jurídicos e Políticos, Florianópolis, n. 77, p. 221-252, nov. 2017.

MACHADO, Hugo de Brito. Transação e arbitragem no âmbito tributário. In: SARAIVA FILHO, Oswaldo Othon de Pontes; GUIMARÃES, Vasco Branco (org.). Transação e arbitragem no âmbito tributário: homenagem ao jurista Carlos Mario da Silva Velloso. Belo Horizonte: Fórum, 2008. p. 111-135.

MARQUES NETO, Floriano de Azevedo. A superação do ato administrativo autista. In: MEDAUAR, Odete; SCHIRATO, Vitor Rhein (coord.). Os caminhos do ato administrativo. São Paulo: RT, 2011. p. 91-113. 
MURPHY, Liam; NAGEL, Thomas. The myth of Ownership: taxes and justice. New York: Oxford University Press, 2002.

NEUMARK, Fritz. Principios de la imposicion. 2. ed. Madrid: Instituto de Estudios Fiscales, 1994.

OLIVEIRA, Gustavo Justino de; SCHWANKA, Cristiane.

A administração consensual como a nova face da Administração

Pública no Sec. XXI: fundamentos dogmáticos, formas de expressão e instrumentos de ação Revista de Direito do Estado, Rio de Janeiro, n. 10, p. 276-277, abr.-jun. 2008.

OLIVEIRA, Ricardo Mariz de. Breves considerações sobre a capacidade contributiva e a isonomia. In: SCHOUERI, Luís Eduardo (coord.). Direito Tributário: homenagem a Alcides Jorge Costa. São Paulo: Quartier Latin, 2003. p. 458-523.

\section{OLLERO, Gabriel Casado. Los fines no fiscales de los tributos:}

comentarios a la Ley General Tributaria y líneas para su reforma. Madrid: Instituto de Estudios Fiscales, 1991. (Libro-homenaje al Professor Sainz de Bujanda).

OTERO, Paulo. Legalidade e Administração Pública: o sentido da vinculação administrativa à juridicidade. Coimbra: Almedina, 2003, p. 894.

RIBAS, Lídia Maria; SILVA, Hendrick Pinheiro. Transação tributária como mecanismo alternativo na resolução de conflitos tributários.

Derecho y Cambio Social, [S.l.], v. 34, p. 1-23, 2013.

ROCHA, Sérgio André. Meios alternativos de solução de conflitos no direito tributário Brasileiro. Revista Dialética de Direito Tributário, São Paulo, n. 122, p. 90-106, nov. 2005.

SANTI, Eurico Marcos Diniz de. Transação e arbitragem no direito tributário: paranoia ou mistificação? In: SARAIVA FILHO, Oswaldo Othon de Pontes; GUIMARÃES, Vasco Branco (org.). Transação e arbitragem no âmbito tributário: homenagem ao jurista Carlos Mário da Silva Velloso. Belo Horizonte: Fórum, 2008. p. 167-190. 
SCHOUERI, Luís Eduardo. Livre concorrência e Tributação. In: ROCHA, Valdir de Oliveira coord. Grandes Questões Atuais do Direito Tributário. São Paulo: Dialética, 2007.

SCHOUERI, Luís Eduardo. Normas tributárias Indutoras e

Intervenção Econômica. Rio de Janeiro: Forense, 2005.

SILVA, Hendrick Pinheiro; RIBAS, Lídia Maria. Transação tributária como ato-negócio administrativo: uma perspectiva de colaboração.

Nomos - Revista do Programa de Pós-Graduação em Direito da UFC, [S.l.], v. 35, n.1, jan.-jun. 2015.

SILVA, José Afonso. Curso de Direito Constitucional Positivo. São Paulo: Malheiros Editores, 2011.

STÖZEL, Martin. Vertrauensschutz und Gesetzesrückwikung. Frankfurt am Main: Peter Lang, 2002. p. 194.

TABOADA, Carlos Palao. El principio de capacidade contributiva como critério de justiça tributaria: aplicación a los impuestos directos e indirectos. In: TÔRRES, Heleno Taveira. (coord.). Tratado de Direito Constitucional Tributário. 5. ed. São Paulo: Saraiva, 2005. p. 285-304.

TAVARES, André Ramos. REFIS: Aceitação das cláusulas pactuadas e os limites do acordo bilateral em face dos direitos individuais. In: VERGUEIRO, Guilherme von Müller Lessa (coord.). REFIS: Aspectos Jurídicos Relevantes. Bauru: EDIPRO, 2001. p. 27-53.

TORRES, Heleno Taveira. Transação, arbitragem e conciliação judicial como medidas alternativas para resolução de conflitos entre Administração e contribuintes: simplificação e eficiência administrativa. Revista de Direito Tributário, São Paulo, v. 86, p. 40-64, out.-dez. 1998.

WESTEN, Peter. Speaking of equality: an analysis of the rhetorical force of "equality" in moral and in legal discourse. Princeton: Princeton University, 1990.

ZILVETI, Fernando Aurélio. Princípio de Direito Tributário e

Capacidade Contributiva. São Paulo: Quartier Latin, 2004. 
ZILVETI, Fernando Aurélio. Variações sobre o Princípio da Neutralidade no Direito Tributário Internacional. Direito Tributário Atual, São Paulo, IBDT, v. 19, p. 24-40, 2005.

Ubaldo César Balthazar é doutor em Direito pela Universidade Livre de Bruxelas. Mestre em Direito pela UFSC. Professor dos Cursos de Graduação e Pós-Graduação da UFSC.

E-mail: ubalth@gmail.com

Endereço profissional: Rua Des. Vítor Lima, n. 222, Trindade, Florianópolis, SC. CEP: $88040-400$.

https://orcid.org/0000-0002-9059-5030

Hendrick Pinheiro é mestre em Direito pela Faculdade de Direito da Universidade de São Paulo (USP). Pesquisador de Doutorado na Faculdade de Direito da Universidade de São Paulo. Advogado.

E-mail: hen_drick@usp.br

Endereço profissional: Avenida Paulista, n. 297, $7^{\circ}$ andar, São Paulo, SP. CEP: 01311-000.

https://orcid.org/0000-0002-4603-2134

Bruno Bartelle Basso é mestre em Direito pela Pontifícia Universidade Católica de São Paulo. Procurador do Estado de Santa Catarina.

E-mail: brunobartelle@gmail.com

Endereço profissional: Rua Arcipreste Paiva, n. 147, Centro, Florianópolis, SC. CEP: 88010-530.

https://orcid.org/0000-0002-8994-8783 